\title{
Artikel
}

\section{De aanvaarding of verwerping van een internationale nalatenschap namens een minderjarige rechthebbende}

\author{
Mr. J.L.D.J. Maasland*
}

\section{Inleiding}

De gerechtigdheid van een minderjarige tot een nalatenschap brengt met zich mee dat in het kader van de afwikkeling aan verschillende waarborgen moet worden voldaan. Zo kan de wettelijke vertegenwoordiger van een minderjarige erfgenaam de nalatenschap niet zuiver anvaarden en behoeft hij voor verwerping op grond van artikel 4:193 lid 1 van het Burgerlijk Wetboek (BW) machtiging van de kantonrechter. In het verlengde daarvan bepaalt artikel 1:345 lid 1 onder c jo. artikel 1:253k BW dat de ouder van een minderjarig kind machtiging van de kantonrechter behoeft voor het namens de minderjarige annemen van een making ${ }^{1}$ (of gift), waaraan lasten of voorwaarden zijn verbonden.

Bij een internationale nalatenschap waartoe een minderjarige wordt geroepen, doet zich de vraag voor of de hiervoor gemelde bepalingen van toepassing zijn. Indien deze vraag bevestigend wordt beantwoord, is de vervolgvraag welke rechter bevoegd is kennis te nemen van het machtigingsverzoek. Mede naar aanleiding van een aantal recente rechterlijke uitspraken, die deels verschil- lende uitkomsten kennen, ga ik in deze bijdrage in op de genoemde vragen.

\section{Toepasselijk recht}

\subsection{Europese Erfrechtverordening}

Zoals bekend is op nalatenschappen die op of na 17 augustus 2015 zijn opengevallen de Europese Erfrechtverordening $(\mathrm{ErfVo})^{2}$ van toepassing. Als uitgangspunt bepaalt artikel 21 lid 1 ErfVo dat op de 'erfopvolging in haar geheel' van toepassing is het recht van de staat waar de erflater op het tijdstip van overlijden zijn gewone verblijfplaats had.

Artikel 22 lid 1 ErfVo biedt de mogelijkheid een rechtskeuze uit te brengen ten aanzien van het op de 'erfopvolging in het geheel' toepasselijke recht. De testateur kan daarbij het recht aanwijzen van de staat waarvan hij de nationaliteit bezit, ten tijde van de rechtskeuze of ten tijde van het overlijden. Bij meervoudige nationaliteit geldt geen toets van de effectieve nationaliteit; in dat geval kan de testateur het recht aanwijzen van een van de staten waarvan hij de nationaliteit bezit. De vormvoorschriften voor de rechtskeuze zijn dezelfde als die voor uiterste wilsbeschikkingen.
* Mr. J.L.D.J. Maasland is notaris bij Loyens \& Loeff N.V. te Amsterdam.

1. I. Breemhaar \& R.E. Brinkman, De aanvaarding namens personae miserabiles van een making, waaraan lasten of voorwaarden zijn verbonden, WPNR 2019, afl. 7263, p. 886-893 betogen dat onder het begrip 'making' in de zin van art. 1:345 lid 1 onder c BW uitsluitend het legaat dient te worden verstaan.
2. Verordening (EU) Nr. 650/2012 van het Europees Parlement en de Raad betreffende de bevoegdheid, het toepasselijke recht, de erkenning en de tenuitvoerlegging van beslissingen en de aanvaarding en de tenuitvoerlegging van authentieke akten op het gebied van erfopvolging, alsmede betreffende de instelling van een Europese erfrechtverklaring, PbEU 2012, L 201/107. 
Artikel 3 lid 1 onder a Erfvo definieert het begrip erfopvolging als:

'de erfopvolging in de nalatenschap van een overleden persoon, waaronder wordt begrepen elke vorm van overgang en overdracht van goederen, rechten en verplichtingen naar aanleiding van een overlijden, ongeacht of het gaat om een vrijwillige overgang of overdracht krachtens een uiterste wilsbeschikking, dan wel om een overgang middels erfopvolging bij versterf'.

Uit deze definitie volgt dat de (wijze van) aanvaarding van een nalatenschap onderdeel uitmaakt van de erfopvolging.

Artikel 1 lid 2 ErfVo zondert een aantal onderwerpen uit van het toepassingsbereik van de ErfVo. Dit betreft onder meer de staat van natuurlijke personen (art. 1 lid 2 onder a ErfVo) en de bekwaamheid van natuurlijke personen (art. 1 lid 2 onder b ErfVo), evenwel onverminderd het bepaalde in artikel 23 lid 2 onder c ErfVo (betreffende de bekwaamheid om te erven) en artikel 26 ErfVo (betreffende de materiële geldigheid van uiterste wilsbeschikkingen).

Een belangrijke vraag is of het verkrijgen van rechterlijke machtiging voor de verwerping van een nalatenschap namens een minderjarige erfgenaam (art. 4:193 lid 1 $\mathrm{BW}$ ), respectievelijk voor de aanvaarding namens de minderjarige van een making waaraan lasten of voorwaarden zijn verbonden (art. 1:345 lid 1 onder c BW), een kwestie van erfrecht of van ouderlijke verantwoordelijkheid/kinderbescherming is. De beantwoording van deze kwalificatievraag is cruciaal om de juiste internationaal-privaatrechtelijke bepalingen toe te kunnen passen.

In zijn arrest van 6 oktober $2015^{3}$ heeft het Europese Hof van Justitie geoordeeld dat de rechterlijke goedkeuring van een overeenkomst tot verdeling van een nalatenschap die voor rekening van minderjarige kinderen is gesloten door de bewindvoerder over hun vermogen, een maatregel is van ouderlijke verantwoordelijkheid en geen kwestie van erfopvolging. In zijn arrest van 19 april $2018^{4}$ oordeelde het Europese Hof van Justitie dat hetzelfde geldt voor de rechterlijke machtiging voor de verwerping van een nalatenschap. Dit betekent dat zowel voor de bepaling van het toepasselijke recht als voor de bepaling van de internationale bevoegdheid van de rechter, de internationaal-privaatrechtelijke verwijzingsregels voor ouderlijke verantwoordelijkheid/ kinderbescherming dienen te worden toegepast.

3. HvJ EU 6 oktober 2015, zaak C-404/14, ECLI:EU:C:2015:653, NJ 2016/241, m.nt. Th.M. de Boer (Matoušková).

4. HvJ EU 19 april 2018, zaak C-565/16, ECLI:EU:C:2018:265, NJ 2018/380, m.nt. Th.M. de Boer (Saponaro en Xylina).

\subsection{Haags Kinderbeschermingsverdrag 1996}

Op grond van artikel 17 van het Haags Kinderbeschermingsverdrag 1996 (HKV 1996) ${ }^{5}$ wordt de uitoefening van de ouderlijke verantwoordelijkheid beheerst door het recht van de staat van de gewone verblijfplaats van het kind. Het machtigingsvereiste van artikel 4:193 lid 1 $\mathrm{BW}$ respectievelijk artikel 1:345 lid 1 onder c BW is dus in ieder geval van toepassing ten aanzien van in Nederland woonachtige minderjarige kinderen. Blijkens artikel 20 kent het HKV 1996 een universeel toepassingsgebied; de verwijzingsregels zijn ook van toepassing indien op grond daarvan het recht van een niet-verdragsluitende staat van toepassing is. Dit betekent dat het $\mathrm{HKV}$ 1996 in alle gevallen, dus ongeacht de gewone verblijfplaats van het minderjarige kind, kan worden toegepast ter bepaling van het op de uitoefening van de ouderlijke verantwoordelijkheid toepasselijke recht.

Artikel 15 lid 1 HKV 1996 bepaalt dat de autoriteiten van de verdragsluitende staten de bevoegdheid die hun ingevolge het bepaalde in Hoofdstuk II van het HKV 1996 is toegekend, als uitgangspunt uitoefenen onder toepassing van hun interne recht (lex fori). Deze zogeheten Gleichlauf-bepaling, die beoogt de eenheid tussen de bevoegde rechter en het toepasselijke recht te bevorderen, is ook van toepassing indien de rechter zijn bevoegdheid niet aan het HKV 1996, maar aan Verordening Brussel II-bis ${ }^{6}$ ontleent. ${ }^{7}$ Indien de minderjarige zijn gewone verblijfplaats in een niet-lidstaat heeft, die evenmin een verdragsstaat is, kan artikel 15 lid $1 \mathrm{HKV}$ 1996 analogisch worden toegepast, aangezien het commune internationaal privaatrecht in Boek $10 \mathrm{BW}$ geen (eigen) verwijzingsregel kent. ${ }^{8}$ Op grond van artikel 15 lid 2 HKV 1996 kan de rechter bij wijze van uitzondering, voor zover de bescherming van de persoon of het vermogen van het kind dit vereist, het recht van een andere staat waarmee de omstandigheden nauw verband houden, toepassen of daarmee rekening houden.

\section{Internationale bevoegdheid}

Zoals hiervoor geconstateerd, vormt het verkrijgen van een machtiging voor de aanvaarding of verwerping van een nalatenschap een onderwerp van ouderlijke verantwoordelijkheid/kinderbescherming, anders dan de (wijze van) aanvaarding van de nalatenschap zelf, dat een erfrechtelijk onderwerp betreft. Hierna zal ik op hoofd-

5. Verdrag inzake de bevoegdheid, het toepasselijke recht, de erkenning, de tenuitvoerlegging en de samenwerking op het gebied van ouderlijke verantwoordelijkheid voor kinderen en maatregelen ter bescherming van kinderen, 's-Gravenhage, 19 oktober 1996, Trb. 1997, 299.

6. Verordening (EG) Nr. 2001/2003 van de Raad van 27 november 2003 betreffende de bevoegdheid en de erkenning en tenuitvoerlegging van beslissingen in huwelijkszaken en inzake de ouderlijke verantwoordelijkheid, en tot intrekking van Verordening (EG) nr. 1347/2000, PbEU 2003, L 338/1.

7. L.Th.L.G. Pellis, T\&C Personen \& Familierecht, art. 15 HKV 1996, aant. 1.

8. Asser/Vonken \& Ibili 10-II 2021/569. 
lijnen ingaan op de internationale bevoegdheidsregels ten aanzien van beide onderwerpen.

\subsection{Rechterlijke machtiging}

Voor de internationale bevoegdheid, ofwel rechtsmacht, van de rechter in zaken betreffende de ouderlijke verantwoordelijkheid voor een minderjarige is de gewone verblijfplaats van de minderjarige bepalend.

De Nederlandse rechter kan aan een aantal regelingen internationale bevoegdheid ontlenen in zaken betreffende de ouderlijke verantwoordelijkheid voor minderjarigen. Dit betreft Verordening Brussel II-bis, het HKV 1996 en de commune bevoegdheidsregels, in het bijzonder artikel 5 van het Wetboek van Burgerlijke Rechtsvordering $(\mathrm{Rv})$.

Op grond van artikel 94 van de Grondwet gaan verdragen en verordeningen boven de wet, hetgeen voor de duidelijkheid wordt herhaald in artikel 10:1 BW en artikel $1 \mathrm{Rv}$. Nederland is zowel gebonden aan Verordening Brussel II-bis als aan het HKV 1996. In geval van samenloop tussen beide regelingen gaat Verordening Brussel II-bis voor indien het minderjarige kind zijn gewone verblijfplaats op het grondgebied van een Verordening Brussel II-bis-lidstaat ${ }^{9}$ heeft. ${ }^{10}$

Artikel 8 lid 1 Verordening Brussel II-bis bepaalt als hoofdregel dat ter zake van de ouderlijke verantwoordelijkheid voor minderjarigen bevoegd zijn de gerechten van de lidstaat op het grondgebied waarvan het minderjarige kind zijn gewone verblijfplaats heeft. Daarnaast kan de Nederlandse rechter internationale bevoegdheid ontlenen aan artikel 12 lid 3 Verordening Brussel II-bis ('prorogatie van rechtsmacht'). Dit is het geval wanneer: (1) de wettelijke vertegenwoordigers van de minderjarige de bevoegdheid van de Nederlandse rechter uitdrukkelijk en ondubbelzinnig aanvaarden, (2) het minderjarige kind een nauwe band met Nederland heeft, met name omdat een van de ouders zijn gewone verblijfplaats in Nederland heeft en/of het kind de Nederlandse nationaliteit bezit, en (3) de uitoefening van de rechtsmacht door het belang van het kind wordt gerechtvaardigd. ${ }^{11}$

Van prorogatie van rechtsmacht krachtens artikel 12 lid 3 Verordening Brussel II-bis kan geen sprake zijn indien de minderjarige zijn gewone verblijfplaats in een buiten de Europese Unie gelegen verdragsluitende staat bij het HKV 1996 heeft. In dat geval is namelijk de bevoegdheidsregel van artikel 5 lid 1 HKV 1996 van toepassing, aangezien geen sprake is van samenloop tussen de Brussel II-bis Verordening en het HKV 1996. Artikel 5 lid 1 HKV 1996 wijst de rechter van de staat van de gewone verblijfplaats van het minderjarige kind aan als de bevoegde rechter.

9. Alle lidstaten van de Europese Unie, met uitzondering van Denemarken (overweging 31 Verordening Brussel II-bis).

10. Zie art. 61 Verordening Brussel II-bis, met als tegenhanger art. 52 lid 2 en 3 HKV 1996.

11. Deze voorwaarden zijn nader uitgewerkt in het in noot 4 genoemde arrest van het Europese Hof van Justitie van 19 april 2018 in de zaak Saponaro en Xylina.
Indien Verordening Brussel II-bis niet leidt tot internationale bevoegdheid van de Nederlandse rechter en dit evenmin het geval is op grond van het HKV 1996, kan de Nederlandse rechter ten slotte in uitzonderlijke gevallen rechtsmacht ontlenen aan artikel $5 \mathrm{Rv} .{ }^{12} \mathrm{Dit}$ is het geval wanneer de Nederlandse rechter zich wegens verbondenheid van de zaak met de rechtssfeer van Nederland in staat acht het belang van het kind naar behoren te beoordelen.

\section{2 (Wijze van) aanvaarding nalatenschap}

Hoofdstuk II van de ErfVo bevat de bevoegdheidsregels in internationale nalatenschappen. Als uitgangspunt bepaalt artikel 4 ErfVo dat de gerechten van de lidstaat waar de erflater op het tijdstip van overlijden zijn gewone verblijfplaats had, bevoegd zijn om uitspraak te doen over de erfopvolging in haar geheel.

In geval van een rechtskeuze zijn de gerechten van een lidstaat waarvan het recht door de erflater overeenkomstig artikel 22 ErfVo is gekozen, bevoegd om over de erfopvolging uitspraak te doen indien: (1) een eerder aangezocht gerecht in de staat van de laatste gewone verblijfplaats van de erflater zich overeenkomstig artikel 6 ErfVo onbevoegd heeft verklaard, (2) de partijen in het geding een forumkeuzeovereenkomst hebben gesloten, dan wel (3) de partijen in het geding de bevoegdheid van het aangezochte gerecht uitdrukkelijk hebben aanvaard.

Ten aanzien van de aanvaarding of verwerping van een nalatenschap bevat artikel 13 ErfVo een aanvullende bevoegdheidsregeling. Deze bepaalt dat naast het gerecht dat overeenkomstig de ErfVo bevoegd is om uitspraak over de erfopvolging te doen, de gerechten van de lidstaat waarin de gewone verblijfplaats van een erfgenaam is gelegen bevoegd zijn een verklaring van beneficiaire aanvaarding of verwerping in ontvangst te nemen. Voorwaarden hiervoor zijn dat: (1) het ingevolge de ErfVo op de erfopvolging toepasselijke recht de mogelijkheid biedt om door middel van het afleggen van een verklaring de aansprakelijkheid voor schulden van de nalatenschap te beperken, en (2) het afleggen van een dergelijke verklaring bij een gerecht volgens het interne recht van de lidstaat van de gewone verblijfplaats van de erfgenaam mogelijk is. De af te leggen verklaring dient te voldoen aan de formele vereisten van het interne recht van de lidstaat van de gewone verblijfplaats van de erfgenaam die de verklaring aflegt (art. 28 onder b ErfVo). Overweging 32 van de considerans van de ErfVo veronderstelt de verplichting voor de betrokken erfgenaam om uit eigen beweging het gerecht of de autoriteit in de lidstaat van de laatste gewone verblijfplaats van erflater die de erfopvolging behandelt, in kennis te stellen van het bestaan van de verklaring die in de lidstaat van de gewone verblijfplaats van de erfgenaam is afgelegd.

12. Zie ook: F. Ibili, De rechtsmachtscheppende betekenis van art. 5 Rv, FJR 2008/68. 
Artikel 2 lid 2 van de Uitvoeringswet Verordening erfrecht ${ }^{13}$ bepaalt dat een wettelijk vertegenwoordiger van een erfgenaam op grond van artikel 13 ErfVo een verklaring zoals bedoeld in artikel 4:193 lid $1 \mathrm{BW}$ kan afleggen ter griffie van de rechtbank van zijn woonplaats. Dit betekent bijvoorbeeld dat de nalatenschap van een Nederlander, die zijn laatste gewone verblijfplaats had in Italië, en die in zijn testament een rechtskeuze voor Nederlands recht heeft uitgebracht, door de in Nederland woonachtige wettelijke vertegenwoordiger van een minderjarige erfgenaam, namens de minderjarige beneficiair kan worden aanvaard door het afleggen van een daartoe strekkende verklaring ter griffie van de rechtbank van de woonplaats van de wettelijk vertegenwoordiger. ${ }^{14}$

\section{Recente uitspraken}

Hierna volgt de bespreking van een aantal recente rechterlijke uitspraken waarin de vragen die het onderwerp van deze bijdrage vormen aan de orde kwamen, met verschillende benaderingen en (daarmee) uitkomsten.

\subsection{Rechtbank Midden-Nederland 29 maart $2018^{15}$}

In deze zaak vroegen de in Nederland woonachtige ouders van twee minderjarige kinderen die ingevolge het testament als erfgenamen waren geroepen in de nalatenschap van een met laatste gewone verblijfplaats in Duitsland overleden erflaatster, de kantonrechter van de rechtbank Midden-Nederland op grond van artikel 4:193 lid 1 BW een machtiging om de nalatenschap namens hun minderjarige kinderen te verwerpen. De nalatenschap van erflaatster werd blijkens de uitspraak ingevolge artikel 21 ErfVo beheerst door Duits recht; kennelijk bevatte het testament dus geen rechtskeuze. De kantonrechter overwoog dat zij bevoegd was om het voorliggende verzoek tot verwerping te behandelen, aangezien de gewone verblijfplaats van de minderjarigen in Nederland was gelegen. $\mathrm{Zij}$ overwoog in dit kader:

'De kantonrechter ziet onder gegeven omstandigheden (DJM: te weten dat de wettelijk vertegenwoordigers van de minderjarigen er niet in slaagden om de nalatenschap in Duitsland te verwerpen) en met inachtneming van de doelstelling van de verordening,

13. Wet van 5 november 2014 tot uitvoering van de Verordening (EU) nr. 650/2012 van het Europees Parlement en de Raad betreffende de bevoegdheid, het toepasselijke recht, de erkenning en de tenuitvoerlegging van beslissingen en de aanvaarding en de tenuitvoerlegging van authentieke akten op het gebied van erfopvolging, alsmede betreffende de instelling van een Europese erfrechtverklaring (PbEU 2012, L 201), Stb. 2014, 430 .

14. Tevens de (afgeleide) woonplaats van de minderjarige; zie art. 1:12 lid 1 BW.

15. ECLI:NL:RBMNE:2018:1223. Zie naar aanleiding van deze uitspraak: J.G. Knot, Verwerping van een nalatenschap namens een minderjarige erfgenaam in internationale gevallen, KWEP 2019/10. In zijn artikel behandelt Knot eveneens de hierna onder 4.2 tot en met 4.5 besproken uitspraken. namelijk het vergemakkelijken van erfrechtprocedures met een Europees karakter, aanleiding om het voorliggende verzoek te behandelen zonder dat het Duitse gerecht hiervan op de hoogte is. Het Nederlandse recht zal hierop worden toegepast. Artikel 13 van de verordening bepaalt namelijk dat een erfgenaam de verklaring voor zijn keuze kan afleggen bij het gerecht van zijn gewone verblijfplaats indien deze verklaringen volgens het recht van die lidstaat in rechte mogen worden afgelegd. Volgens het recht van deze lidstaat (Nederland) kunnen verzoekers de nalatenschap namens de minderjarigen met machtiging van de kantonrechter verwerpen.'

\subsection{Rechtbank Den Haag 2 juli $2018^{16}$}

In deze zaak verzochten de wettelijke vertegenwoordigers van twee in Australië woonachtige minderjarige kinderen de kantonrechter van de rechtbank Den Haag een machtiging om een in Nederland opengevallen nalatenschap namens de minderjarigen te verwerpen. De kantonrechter oordeelde dat op grond van artikel 5 HKV 1996 het gerecht van de verdragsluitende staat waar de minderjarigen hun gewone verblijfplaats hebben, bevoegd is over het verzoek te oordelen. Aangezien Australië een verdragsluitende staat bij het HKV 1996 is, verklaart de Nederlandse kantonrechter zich onbevoegd.

Ten overvloede overweegt de kantonrechter dat, gelet op artikel 17 HKV 1996, de vraag of de wettelijke vertegenwoordigers een rechterlijke machtiging nodig hebben om de nalatenschap namens de minderjarigen te verwerpen, dient te worden beoordeeld naar Australisch recht. De kantonrechter stelt daarbij:

'Als, zoals verzoekers stellen, naar Australisch recht geen machtiging nodig is voor de verwerping namens minderjarigen, dient de bevoegde rechtbank van het sterfhuis van erflater de verklaring tot verwerping in ontvangst te nemen en in te schrijven in het boedelregister. Aan het in ontvangst nemen van de verklaring tot verwerping en de inschrijving daarvan in het boedelregister kan in dat geval niet de voorwaarde worden verbonden dat daartoe een rechterlijke machtiging wordt verstrekt.'

\subsection{Rechtbank Den Haag 18 september $2018^{17}$}

In deze zaak verzochten de wettelijke vertegenwoordigers van een in Indonesië woonachtig minderjarig kind de kantonrechter een machtiging om een in Nederland opengevallen nalatenschap namens de minderjarige te verwerpen. Indonesië is geen verdragsluitende staat bij het HKV 1996. De kantonrechter oordeelde dat hij

16. ECLI:NL:RBDHA:2018:7849, besproken in Notamail 2018-205. Zie naar aanleiding van deze uitspraak en de hierna te vermelden uitspraak van de Rechtbank Den Haag van 18 september 2018: S.H. Heijning, Welke rechter is bevoegd kennis te nemen van het verzoek tot machtiging om een internationale nalatenschap te verwerpen namens een minderjarige erfgenaam?, WPNR 2019, afl. 7253, p. 685-688.

17. ECLI:NL:RBDHA:2018:13811. 
dientengevolge aan de hand van artikel $5 \mathrm{Rv}$ diende te bepalen of hem rechtsmacht toekwam.

Aangezien de gewone verblijfplaats van het minderjarige kind buiten Nederland was gelegen en er naar het oordeel van de kantonrechter geen sprake was van een uitzonderlijk geval waarbij de Nederlandse rechter zich wegens de verbondenheid van de zaak met de rechtssfeer van Nederland in staat acht het belang van het kind naar behoren te beoordelen, verklaart de kantonrechter zich onbevoegd om op het verzoekschrift te beslissen. Het enkele feit dat de minderjarige de Nederlandse nationaliteit bezit, is volgens de kantonrechter onvoldoende om tot het oordeel te komen dat het kind een zodanige verbondenheid met Nederland heeft dat de Nederlandse rechter bevoegd is te oordelen over het machtigingsverzoek. Het feit dat de nalatenschap in Nederland wordt afgewikkeld, zegt alleen iets over de verbondenheid van de nalatenschap met Nederland, maar niets over de verbondenheid van de minderjarige met Nederland, aldus de kantonrechter.

In haar commentaar op deze uitspraak merkt Heijning ${ }^{18}$ op dat naar haar mening de kantonrechter zijn bevoegdheid had moeten baseren op de Verordening Brussel IIbis en niet op artikel $5 \mathrm{Rv}$. Op grond van prorogatie krachtens artikel 12 lid 3 Verordening Brussel II-bis had de kantonrechter in deze zaak mogelijk rechtsmacht kunnen aannemen.

\subsection{Rechtbank Limburg 30 oktober $2018^{19}$}

In deze zaak verzocht de wettelijk vertegenwoordiger de kantonrechter een machtiging om een in Nederland opengevallen nalatenschap namens haar twee in Polen woonachtige minderjarige kinderen te verwerpen. De kantonrechter gaat voorbij aan de vraag of hem in casu rechtsmacht toekomt. Hij concludeert dat ingevolge de ErfVo Nederlands recht van toepassing is op de nalatenschap. Als gevolg van een eerdere verwerping door een meerderjarige erfgenaam in de eerste parentele (art. 4:10 lid 1 onder a $\mathrm{BW})$, zijn de minderjarigen bij wege van plaatsvervulling als erfgenamen tot de nalatenschap geroepen. Aangezien de eerdere verwerping reeds meer dan drie maanden geleden had plaatsgevonden, leidt (strikte) toepassing van artikel 4:193 lid 2 BW ertoe dat de minderjarigen geacht worden de nalatenschap beneficiair te hebben aanvaard (met de wettelijke vereffening als gevolg). Mede gelet op een eerder in Polen genomen rechterlijke beslissing, en om te voorkomen dat de minderjarigen door onkunde van een meerderjarige de nalatenschap zouden dienen te vereffenen, verleent de kantonrechter machtiging om de nalatenschap namens de minderjarigen te verwerpen.

\subsection{Rechtbank Midden-Nederland 20 februari $2019^{20}$}

Deze zaak betrof een verzoek tot machtiging voor de verwerping van een nalatenschap namens twee in Nederland woonachtige minderjarige kinderen. Op basis van de relevante feiten en omstandigheden concludeert de kantonrechter dat de laatste gewone verblijfplaats van de overledene in Polen was gelegen, waardoor zijn erfopvolging op grond van artikel 21 lid 1 ErfVo door Pools recht wordt beheerst. Gelet op de gewone verblijfplaats van de minderjarigen in Nederland acht de kantonrechter zich bevoegd over het machtigingsverzoek te oordelen. Op basis van artikel 13 ErfVo acht de kantonrechter het mogelijk om de nalatenschap in Nederland te verwerpen met inachtneming van de hiertoe door het Nederlandse recht voorgeschreven formaliteiten.

\subsection{Rechtbank Den Haag 5 december $2019^{21}$}

Deze zaak betrof het verzoek tot machtiging om een in Nederland opengevallen nalatenschap te verwerpen namens een in Duitsland woonachtige minderjarige. De kantonrechter overweegt dat, gelet op het feit dat de minderjarige haar gewone verblijfplaats in Duitsland heeft op grond van artikel 8 Verordening Brussel II-bis in beginsel de rechter in Duitsland bevoegd is om op het verzoek te beslissen. Op basis van prorogatie krachtens artikel 12 lid 3 Verordening Brussel II-bis kan evenwel ook de Nederlandse rechter bevoegd zijn. De kantonrechter overweegt in dit kader:

'Uit de beschikbare informatie blijkt dat de minderjarige zowel de Duitse als de Nederlandse nationaliteit heeft. Daaruit blijkt dat de minderjarige een nauwe band met Nederland heeft. Verder hebben verzoekers door het gezamenlijk indienen van hun verzoek de bevoegdheid van de Nederlandse rechter op ondubbelzinnige wijze aanvaard. Tot slot wordt de nauwe band die de minderjarige met Nederland heeft nog versterkt door het feit dat de erflater in Nederland woonde en de nalatenschap zich in Nederland bevindt. Nu er geen aanwijzingen zijn voor het tegendeel, staat daarmee voldoende vast dat de bevoegdheid van de Nederlandse rechter door het belang van de minderjarige wordt gerechtvaardigd. De kantonrechter acht zich dus bevoegd om van het verzoek kennis te nemen.'

De kantonrechter stelt vast dat op grond van artikel 17 HKV het machtigingsverzoek naar Duits recht dient te worden beoordeeld, zijnde het recht van de gewone verblijfplaats van de minderjarige. Naar het recht van Duitsland (artikel 1643 Bürgerliches Gesetzbuch) hebben de ouders toestemming van de familierechtbank nodig om namens de minderjarige een nalatenschap te verwerpen, tenzij het minderjarige kind erfgenaam is geworden als gevolg van de verwerping van de nalatenschap door een van die ouders. In dit geval was de minderjarige als gevolg van verwerping door haar vader tot 
de nalatenschap geroepen. In die situatie is geen machtiging van de rechter vereist. Gelet daarop wijst de kantonrechter het verzoek af bij gebrek aan belang.

\subsection{Rechtbank Den Haag 20 juli $2020^{22}$}

In deze zaak verzochten de wettelijke vertegenwoordigers van drie in Oostenrijk woonachtige minderjarige kinderen de kantonrechter van de rechtbank Den Haag machtiging om de nalatenschap van een in België overleden erflater te verwerpen. Op basis van prorogatie krachtens artikel 12 lid 3 Verordening Brussel II-bis acht de kantonrechter zich bevoegd over het verzoek te oordelen. De hiervoor vereiste nauwe band met Nederland leidt de kantonrechter af uit het feit dat de kinderen de Nederlandse nationaliteit hebben. Door het gezamenlijk indienen van het machtigingsverzoek hebben de verzoekers de bevoegdheid van de Nederlandse rechter op ondubbelzinnige wijze anvaard. Op basis van artikel $17 \mathrm{HKV}$ beoordeelt de kantonrechter het machtigingsverzoek naar het recht van Oostenrijk.

\subsection{Gerechtshof Den Haag 11 november $2020^{23}$}

In deze zaak had de kantonrechter in eerste aanleg geoordeeld dat hem op grond van artikel $5 \mathrm{Rv}$ geen rechtsmacht toekwam om te oordelen over een verzoek door twee ouders tot machtiging om een in Nederland opengevallen nalatenschap namens hun twee minderjarige kinderen met gewone verblijfplaats in de Verenigde Staten te verwerpen.

In hoger beroep oordeelt het hof allereerst dat het machtigingsverzoek van de ouders voor internationaal-privaatrechtelijke doeleinden dient te worden gekwalificeerd als een kwestie van ouderlijke verantwoordelijkheid en niet als een kwestie van erfrecht. Anders dan de ouders betoogden, bleef de Europese Erfrechtverordening in dit geval derhalve buiten toepassing. Aangezien de minderjarigen hun gewone verblijfplaats in de Verenigde Staten hebben, komt de Nederlandse rechter op grond van artikel 8 Verordening Brussel II-bis geen rechtsmacht toe. Het hof ziet geen aanleiding om prorogatie krachtens artikel 12 lid 3 Verordening Brussel IIbis aan te nemen, aangezien de hiertoe vereiste nauwe band met Nederland naar het oordeel van het hof ontbreekt, met name omdat de minderjarigen niet de Nederlandse nationaliteit hebben.

$\mathrm{Nu}$ de Verenigde Staten geen partij zijn bij het HKV 1996, dient de rechtsmacht van de Nederlandse rechter te worden bepaald op grond van de commune regels van internationaal bevoegdheidsrecht, in het bijzonder op grond van artikel $5 \mathrm{Rv}$. Het hof is van oordeel dat de Nederlandse rechter in dit geval rechtsmacht kan ontlenen aan artikel $5 \mathrm{Rv}$ en motiveert dit oordeel als volgt:

'Buiten de toepassing van verdragen en verordeningen, bepaalt artikel $5 \mathrm{Rv}$ dat de Nederlandse rechter in zaken van ouderlijke verantwoordelijkheid geen rechtsmacht heeft, indien de minderjarige zijn gewo- ne verblijfplaats niet in Nederland heeft (zie ook HR 27 april 2007, ECLI:NL:HR:2007:AZ77772). In uitzonderlijke gevallen heeft artikel $5 \mathrm{Rv}$ echter ook een rechtsmachtscheppende betekenis, namelijk wanneer de Nederlandse rechter zich wegens de verbondenheid van de zaak met de rechtssfeer van Nederland in staat acht het belang van de minderjarige naar behoren te beoordelen.'

Het hof ziet in de omstandigheid dat de minderjarigen als erfgenamen worden geroepen tot de in Nederland opengevallen nalatenschap van erflater, voldoende aanknopingspunten om rechtsmacht te kunnen aannemen op grond van artikel $5 \mathrm{Rv}$. Daarbij heeft het hof laten meewegen dat de nalatenschap negatief is en de vermogensrechtelijke belangen van de minderjarigen gediend zijn bij een beslissing over de verzochte machtiging tot verwerping van de nalatenschap. Op grond van artikel 15 lid 1 HKV (lex fori) beoordeelt het hof het machtigingsverzoek volgens Nederlands recht.

\subsection{Rechtbank Den Haag 25 februari $2021^{24}$}

De meest recente uitspraak die in dit kader wordt besproken, betreft het verzoek van de ouders van twee in Italië woonachtige minderjarige kinderen tot machtiging om een in Nederland opengevallen nalatenschap te verwerpen. Gelet op de gewone verblijfplaats van de minderjarigen is op grond van het bepaalde in artikel 8 lid 1 Verordening Brussel II-bis in beginsel de rechter in Italië bevoegd om te beslissen op het verzoek. Niettemin verklaart de Nederlandse kantonrechter zich op basis van prorogatie krachtens artikel 12 lid 3 Verordening Brussel II-bis internationaal bevoegd. $\mathrm{Nu}$ op grond van artikel 262 tot en met $268 \mathrm{Rv}$ geen andere rechter wordt aangewezen, is de kantonrechter te Den Haag (relatief) bevoegd op het onderhavige verzoekschrift te beslissen. Gelet op het bepaalde in artikel $17 \mathrm{HKV}$ beoordeelt de kantonrechter het machtigingsverzoek naar het recht van Italië, aangezien de minderjarigen aldaar hun gewone verblijfplaats hebben.

In haar noot bij deze uitspraak stelt Heijning, ${ }^{25}$ mijns inziens terecht, dat de kantonrechter op basis van artikel 15 lid 1 HKV 1996 als de lex fori Nederlands recht had moeten toepassen, aangezien het geven van toestemming voor verwerping namens een minderjarige naar haar mening moet worden aangemerkt als een maatregel in de zin van artikel 15 HKV 1996.

\section{Conclusie}

De vraag of rechterlijke machtiging is vereist voor de verwerping van een nalatenschap namens een minderjarige erfgenaam respectievelijk de aanvaarding namens een minderjarig kind van een making waaraan lasten en voorwaarden zijn verbonden, betreft de uitoefening van 
ouderlijke verantwoordelijkheid voor minderjarigen en geen kwestie van erfopvolging. Dit betekent dat ter bepaling van de internationale bevoegdheid van de Nederlandse rechter en ter bepaling van het toepasselijke recht, de internationaal-privaatrechtelijke verwijzingsregels betreffende ouderlijke verantwoordelijkheid/kinderbescherming dienen te worden gevolgd.

Indien de gewone verblijfplaats van de minderjarige in Nederland is gelegen, komt de Nederlandse rechter op grond van artikel 8 lid 1 Verordening Brussel II-bis rechtsmacht toe. Indien de gewone verblijfplaats van de minderjarige buiten Nederland is gelegen, kan de Nederlandse rechter bij voldoende verbondenheid met de Nederlandse rechtssfeer in bepaalde gevallen internationale bevoegdheid aannemen, door prorogatie krachtens artikel 12 lid 3 Verordening Brussel II-bis, dan wel op basis van artikel $5 \mathrm{Rv}$.

Indien de Nederlandse rechter rechtsmacht toekomt, zal hij op basis van rechtstreekse of analogische toepassing van artikel 15 lid $1 \mathrm{HKV} 1996$ bij de beoordeling van het machtigingsverzoek in beginsel Nederlands recht dienen toe te passen, als de lex fori. In uitzonderingsgevallen kan de Nederlandse rechter, voor zover de bescherming van de persoon of het vermogen van het kind dit vereist, het recht van een andere staat waarmee de omstandigheden nauw verband houden, toepassen of daarmee rekening houden.

Uit de hiervoor besproken jurisprudentie blijkt het belang van de juiste kwalificatie van het onderhavige vraagstuk om de juiste verwijzingsregels ten aanzien van de internationale bevoegdheid van de Nederlandse rechter te hanteren. Zoals door het gerechtshof Den Haag in zijn hiervoor besproken arrest van 11 november 2020 is bevestigd, past de Nederlandse rechter indien hij rechtsmacht aanneemt als uitgangspunt op grond van artikel 15 lid 1 HKV 1996 als lex fori het Nederlandse recht toe. Toepassing van het recht van de gewone verblijfplaats van de minderjarige op basis van artikel 17 HKV 1996, zoals in meerdere van de hiervoor besproken uitspraken is gebeurd, is gelet daarop niet juist.

Op de aanvaarding of verwerping van de nalatenschap zelf is de ErfVo van toepassing. Indien de erflater met laatste gewone verblijfplaats buiten Nederland is overleden, kan de nalatenschap namens de minderjarige beneficiair aanvaard of verworpen worden ter griffie van de rechtbank van de in Nederland woonachtige wettelijke vertegenwoordiger van de minderjarige. Op de formele vereisten voor de beneficiaire anvaarding respectievelijk verwerping is in dat geval het Nederlandse recht van toepassing. 